\title{
Digital Maturity of Higher Education Institutions in Bosnia and Herzegovina: Teachers' Assessment
}

\author{
Mirela Mabić \\ University of Mostar, Faculty of Economics, Bosnia and Herzegovina \\ Daniela Garbin Praničević \\ University of Split, Faculty of Economics, Business and Tourism, Croatia
}

\begin{abstract}
This paper presents the research results on digital maturity in higher education institutions in Bosnia and Herzegovina $(\mathrm{BiH})$. Empirical research was conducted among employees of eight public higher education institutions in spring 2020. Digital maturity was examined through seven dimensions. The results show that higher education institutions in $\mathrm{BiH}$ started the digitalization process more than five years ago. They have been continuously working on the digitalization of all business processes and activities. According to employees, on a scale from 1 to 5, digitalization of their higher education institutions is somewhere in the middle (between 3 and 4). The institutions have room for improvement in all dimensions.

Keywords: digital maturity, higher education, digitalization

JEL classification: I23, L86

Paper type: Research article

Received: Jul 8, 2021

Accepted: Aug 8, 2021

DOI: 10.54820/RAKW8731
\end{abstract}




\section{Introduction}

Modern technologies, such as social software, data analysis, clouds, Internet of Things, are revolutionizing the daily operations of modern organizations on all possible levels and in all possible ways. Moreover, it was expected that "digital transformation" had recently become one of the most prevailing Internet concepts (Kokkinakos et al., 2016). Setia et al. (2013) state that rapid and continuous change and improvement of technology, as well as rapid adoption of digital products and services by consumers in recent years, are key forces of digitalization or digital transformation in the modern era, requiring companies to digitize their sales and communication channels further and digitally increase or replace physical products and services.

According to Clark (2018), the digital transformation includes applying technology to transform the organization's core business to meet clients/customers' needs. In the context of higher education, this author views digital transformation primarily from students' point of view as primary users of higher education services and analyzes the changes that digital technologies, through digital transformation, can provide for them. Thus, he points out that perceiving the digital transformation in the context of reshaping the student experience would include a series of changes (according to Clark, 2018), such as: attracting future students digitally using social media and text messages, allowing students to register on student information systems via mobile phones in the cloud, providing different online learning options so that students have enough different opportunities to choose key courses/courses in their academic careers, use technology to monitor student progress and performance and execute intervention protocols, establish partnerships with the industry due to digital badges and certifications which would improve the student's chances of achieving a successful career.

Matković et al. (2018) state that digital transformation in higher education aims to redefine educational services and products and renew operational processes using one of three approaches: first service transformation, first process transformation, combined, the simultaneous transformation of both services and processes.

Sandkuhl et al. (2017) point out that digital transformation in higher education aims to redefine educational services and redesign all business processes.

As drivers of digital transformation in the higher education sector, Alcatel-Lucent Enterprise (2019) highlights various issues facing higher education institutions: campus security issues, information security, student success, IT strategy, student services, accessibility, digital integration, artificial intelligence. The authors also state that digitally transforming higher education institutions would not only include updated hardware and software (without diminishing their importance in the digital transformation process) but they also emphasize the following factors: building a strong IT foundation, encouraging successful students, creating a secure campus, ensuring superior cyber security and operational efficiency. For these authors, the digital transformation of higher education institutions represents a physical and philosophical change designed to meet the growing demands of students, colleges, and campuses to create a learning environment in which everything is connected. Digital transformation creates an ecosystem or an intelligent campus that combines technology, services, and security to bridge the digital divide and create a collaborative, interactive, and customized learning experience.

As interesting and great facilitations that digital technology brings to the educational institutions, Spear (2019) lists the following: library digitalization, conversation agents, online questions/answers, digital notes, facilitated studying, 
digital payment, online curriculum / online learning, informative applications, digitally controlled systems, and decision making based on data analysis.

EHL Insights (2020) points out that online learning is just how digital technologies and advancements have influenced students and classroom trends. Consequently, the author cites the following trends that, under the influence of digital technology, have occurred and are still occurring in the educational process: improved accessibility and access, adapted access to learning, virtual reality, cloud-based learning, the inclusion of related things (IOT) in the educational environment, security, teaching digital citizenship, big data.

Reflecting on all the benefits of digitalization and its inevitability, the authors decided to investigate the situation in higher education institutions in $\mathrm{BiH}$. Accordingly, the paper aimed to investigate the digital transformation in higher education institutions in $\mathrm{BiH}$ - when digitalization began and how far it has reached.

After this introduction, which gives a brief overview of the digital transformation in higher education, its drivers and strengths, and highlights the paper's aim, follows a methodology that describes the instrument and process of data collection and statistical analysis. After that, the results of the conducted research were presented, discussed, and conclusions were made concerning future research in this area.

\section{Methodology}

The empirical research was conducted among employees of eight public universities in BiH during May and June 2020.

A digital maturity measurement model developed by Đurek et al. (2018) was used to assess digital maturity. This model is based on seven key domains and 45 statements. Questions on the beginning of digitization and the \% of business activities/processes that were digitized by the survey were added to the questionnaire and the question on the first digitized business activity/process. Respondents also had the opportunity to evaluate the digitalization of their institution according to their assessments.

An online survey was conducted. The survey questionnaire was created using the Google Forms option. The invitation to participate in the survey with the link to access the survey questionnaire was distributed by email. The official email addresses of the teachers were taken from the official websites of the faculties of public universities in $\mathrm{BiH}$. According to the data available on the official website of the faculties (established units) of public universities in $\mathrm{BiH}$, the population of teachers consisted of 4328 teachers. A total of 3709 emails (85.7\% of the teacher population) were collected. They were invited to participate in the survey, and 665 of them responded to the call, which is $17.93 \%$ of the total emails sent. After receiving the email, 11 teachers responded and informed that they were no longer employed at the faculties of public universities in $\mathrm{BiH}$ - they were external associates (no longer) or retired. The return rate was $18 \%$.

IBM SPSS Statistics 25 (IBM SPSS Statistics for Windows, version 25.0, Armonk, NY: IBM Corp., released 2017) and Microsoft Excel (Office version 2016, Microsoft Corporation, Redmont, WA, USA) were used for statistical data analysis.

Descriptive statistics procedures were used to describe the collected data: frequencies (absolute and relative, \%), measures of central tendency (mean, mode, median), quartiles, and measures of variability (standard deviation and coefficient of variation).

The reliability, i.e., the internal consistency of the items within dimensions, was investigated by the Cronbach Alpha coefficient to measure the internal consistency of a set of statements. This coefficient can take a value between 0 and 1 ; the closer 
to the value of 1 , the more reliable the measurement scale. Cronbach's Alpha coefficient values of 0.7 upwards can be considered acceptable (Nunnally et al., 1994). The results are shown in the tables on the graphs.

\section{Results}

The Cronbach Alpha coefficient values for the digital maturity dimensions are shown in Table 1.

Table 1

Cronbach Alpha coefficient for digital maturity dimensions

\begin{tabular}{lllll}
\hline No & Dimension & $\begin{array}{l}\text { Number of } \\
\text { claims }\end{array}$ & $\begin{array}{l}\text { Cronbach } \\
\text { Alpha }\end{array}$ \\
\hline 1 & LPaM & Leadership, planning, and management & 7 & 0.935 \\
\hline 2 & LaT & Learning and teaching & 5 & 0.902 \\
\hline 3 & SRW & Scientific-research work & 6 & 0.907 \\
\hline 4 & TTaStoS & Technology transfer and service to the society & 5 & 0.920 \\
\hline 5 & ICTC & ICT culture & 8 & 0.913 \\
\hline 6 & ICTI & ICT infrastructure & 7 & 0.936 \\
\hline 7 & QA & Quality assurance & 7 & 0.922 \\
\hline
\end{tabular}

Source: Author's calculation

Based on the results shown in the previous table and the reference values from the literature, it can be concluded that the dimensions of digital maturity have excellent internal consistency.

The mean value of dimensions of digital maturity ranged between 3 and 4 , more precisely in the interval $[3.35 ; 3.88$ ]. The digital maturity dimension with the highest mean is "ICT culture," and the dimension with the lowest mean is "Technology transfer and service to society." The coefficients of variation indicate the relatively satisfactory representativeness of means.

Descriptive statistics for digital maturity dimensions are shown in Table 2, and Figure 1 presents the mean values of individual dimensions of digital maturity.

Table 2

Descriptive statistics for digital maturity dimensions

\begin{tabular}{llllllll}
\hline No & Dimension & M & SD & CV & C & Q1 & Q3 \\
\hline 1 & LPaM & 3,50 & 1,02 & $29,1 \%$ & 3,71 & 2,71 & 4,33 \\
\hline 2 & LaT & 3,64 & 1,00 & $27,5 \%$ & 3,80 & 3,00 & 4,40 \\
\hline 3 & SRW & 3,38 & 1,02 & $30,2 \%$ & 3,50 & 2,67 & 4,17 \\
\hline 4 & TTaStoS & 3,35 & 1,09 & $32,5 \%$ & 3,40 & 2,60 & 4,20 \\
\hline 5 & ICTC & 3,88 & 0,86 & $22,2 \%$ & 4,00 & 3,25 & 4,57 \\
\hline 6 & ICTI & 3,73 & 0,99 & $26,5 \%$ & 4,00 & 3,00 & 4,57 \\
\hline 7. & QA & 3,56 & 1,05 & $29,5 \%$ & 3,71 & 3,00 & 4,43
\end{tabular}

Abbreviation: $M$ - mean; SD - standard deviation; CV - coefficient of variation; C - median; Q1 - first quartile; Q3 - third quartile Source: Author's calculation 
Figure 1

Mean value of digital maturity dimensions

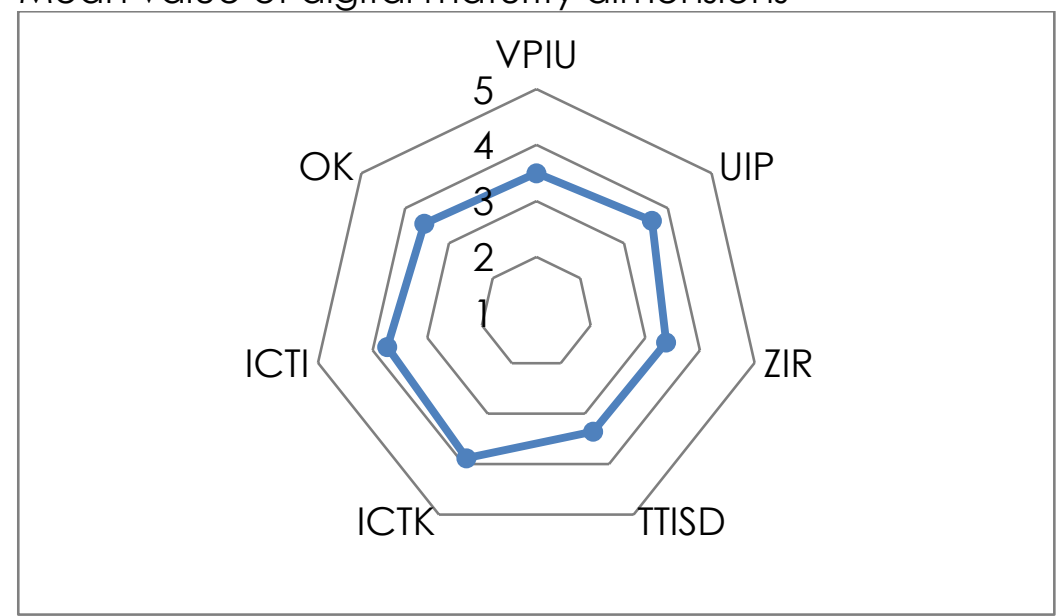

Source: Author's illustration

The mean for all dimensions (digital maturity score) is 3.59 with a standard deviation of 0.85 (coefficient of variation is $23.67 \%$ ). The median is 3.72 , and the lower and upper quartiles are 2.59 and 4.29 , respectively.

In addition to assessing digitalization according to the offered digital maturity model, teachers gave their assessment of digitalization of the faculties where they work. The mean score for this question is 3.36, with a standard deviation of 0.92 (coefficient of variation is $27.38 \%$ ). The median grade is 3.0 for the first quartile, 3.0, and the third quartile 4.0.

Teachers' assessment of digitalization differs significantly from the assessment obtained based on the questionnaire for digital maturity assessment $(Z=-8.706 ; p$ $<0.001$; Wilcoxon rank test). From the teachers' point of view, the digital maturity assessment is significantly lower than the assessment of digital maturity obtained with the used questionnaire.

Furthermore, respondents were asked to give a free estimate of the share of digitized business processes/activities in the total number of business processes/activities at their faculties. In total, 629 respondents responded by stating the exact percentage/share, 22 answered that "I do not know," while 14 commented on the COVID-19 pandemic, but they didn't state the exact share/percentage.

According to these 14 respondents, thanks to the COVID-19 pandemic, the faculties have made significant progress in digitalization. This pandemic has caused, and still causes, major and significant changes in the way the teaching process is implemented. As expected, the range of shares varies from 0 to $100 \%$, and the answers were grouped into four categories. The distribution of respondents according to the formed categories of answers is shown in Figure 1. 
Figure 1

Distribution of answers to the question "share of digitized activities/business processes in the total number of activities/business processes at faculties."

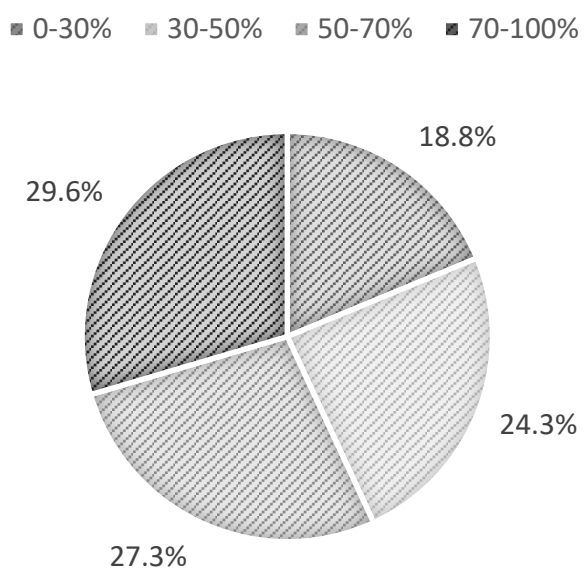

Source: Author's illustration

In addition to the above question, it was also required to identify the activities or business processes that were first digitized. The answers for most teachers were: administration, student work, and exam registration.

More than half of the teachers stated that digital transformation at their faculties started before 2016, which means that it lasts more than five years $163.3 \%$ before $2016,36.7 \%$ after 2016).

The distribution of teachers' answers to the question about the beginning of digitalization at their faculties is shown in Figure 2.

Figure 2

Distribution of answers to the question about the start time of digitalization

abefore 2016 a $2016 \quad 2017 \quad 2018=2019 \square 2020$

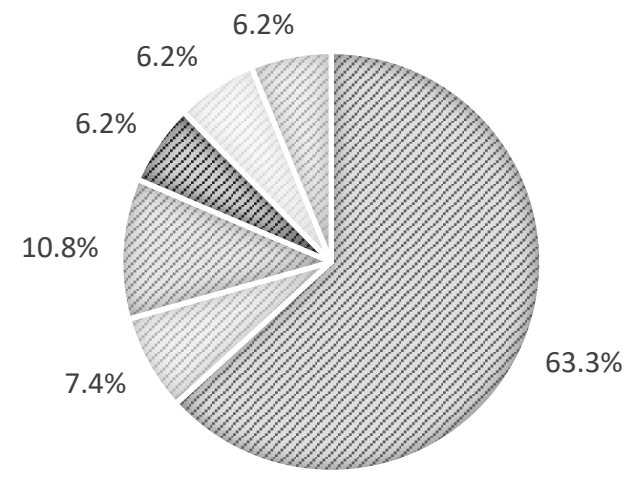

Source: Author's illustration

\section{Discussion}

The analysis of the obtained results shows that higher education institutions in $\mathrm{BiH}$ are only in the middle of the digital transformation road. This was derived as a conclusion of the obtained results in terms of digital maturity. The average digital maturity score is 3.59, and around this rating are ratings of individual dimensions [3.35 - 3.88]. 
Although it can be noticed that the mean grade of digital maturity is closer to grade 4 than grade 3 , this still does not provide enough basis to draw a different conclusion from the one made at the beginning of the discussion - "only in the middle of the road." This middle ground is best interpreted through the dimensions of digital transformation but also the claims they involve.

The dimension with the highest mean grade is the "ICT culture" dimension, and the dimension with the lowest mean grade is the "Technology transfer and service to society" dimension. These dimensions themselves show that higher education institutions in $\mathrm{BiH}$ pay attention to developing a culture oriented to information and communication technologies (ICT) but do not make sufficient use of ICT in the practical application of acquired knowledge.

According to the teachers 'opinions, the results pointed out that a significant difference was found in the university's digital maturity and the digitalization assessment. Teachers gave significantly lower scores than indicated by the digital maturity rating questionnaire (3.36 vs. 3.59). The reasons for this can be multiple, but firstly, goals and the digitalization plan should be reviewed, and special attention should be paid to their implementation. In addition, it should be investigated whether there is a well-defined, continuous and systematic approach to the digitalization of business activities at all. It is also possible that everything exists "on paper" but that the above was not implemented in practice or was not sufficiently implemented (to a defined extent). Of course, it is possible to have a difference in understanding digitalization and business activities that should be first digitized. Still, it should be considered that, often, the management of higher education institutions has a broader view of the functioning and business of higher education institutions. Therefore, before making any general conclusions about the reasons for the differences in the assessment of digitalization, a new survey with a broader focus on business should be conducted.

Although more than half of the teachers stated that more than half of their business processes/activities had been digitized at their faculties, the question is how much they have been digitized. What is the level of digital maturity of precisely these business processes/activities? It is assumed that they changed the way of working and the practice that prevailed ten years ago. They have likely introduced technology into their business, but that does not mean that they have achieved top solutions in terms of digitalization. The real picture of digital transformation and digital maturity of $\mathrm{BiH}$ institutions would be acquired only after comparing with world universities that, perhaps, have not implemented technology any longer than the university in $\mathrm{BiH}$. Still, the solutions they use in their business activities are far more advanced than in $\mathrm{BiH}$. Comparison with the best practices could be a real impetus for more intensive digitalization of education in $\mathrm{BiH}$, not only in higher education but also in other levels of education. Suppose we add to that the fact that a significant number of private higher education institutions operate in $\mathrm{BiH}$, which creates immense competitive pressure on public higher education institutions. In that case, it is more than obvious that higher education institutions included in this research must significantly intensify all activities in the field of digitalization. Perhaps, the "opponents" of digital technologies and digitalization, in general, will say that the essence of education is not in digitalization and that the acquisition of knowledge does not necessarily depend on technology and, while they may be right, today's society imposes technology in all spheres in such a way that educational institutions must adapt and continuously adopt new trends. This must be imperative, especially because new generations are practically born with technology, use it in all possible fields, and digitalization solves physical/geographical distance. 
Suppose we start from the fact that the provision of education services is the primary or at least one of higher education institutions' primary activities and that students are their primary stakeholders. In that case, it is understandable first to improve the quality and digitalization of business activities. As expected, digitalization was first carried out in the administration department, emphasizing the administrative affairs of the student service and the exam application process. This improves students' satisfaction and significantly contributes to the satisfaction of other indirect stakeholders - parents, competent institutions, the economy, and the wider community.

More than half of the teachers indicate that their institutions started digitalization before 2016, i.e., the digital transformation of business at their institutions has been carried out for more than five years. If this result is viewed in the context of assessing digital maturity and satisfaction with digitalization, the question arises: "Why are these results not better." It should be kept in mind that digitalization is an ongoing process that cannot be completed due to daily improvements and new solutions in digital technology. Significant obstacles to better results may be people, their nonacceptance and difficulty in acceptance of technology, different attitudes towards technology, different views of the educational process, and sometimes even rejection and conscious sabotage of all activities undertaken by the higher education institution. Of course, it should always keep in mind that doing business in a turbulent, dynamic, and highly competitive environment can impose different requirements that can interfere with all plans of higher education institutions, including plans related to digitalization.

\section{Conclusion}

The obtained results show that higher education institutions in $\mathrm{BiH}$ have recognized the importance of digital transformation, and they are going in the right direction. Still, they also have a lot of room for improvement in their digital maturity.

Several facts confirm this: more than half of the institutions have been digitized for five years, the average ratings of the surveyed dimensions range between 3 and 4 , and slightly more than $50 \%$ of business processes/activities have already been digitized. These items urgently need to be improved, which means that higher education institutions need to make more efforts to achieve a satisfactory level of digital maturity, which would bring significant benefits to all stakeholders in higher education.

The conducted research also had certain limitations related to the size and characteristics of the sample. The survey was conducted among employees, primarily teachers of higher education institutions, employed at faculties belonging to different fields of science. The sample covered $18 \%$ of the population, and it includes different areas of science and related fields, which may affect the results obtained. Further research activities should be based on the obtained results and limitations of the conducted research. First of all, the sample should be enlarged and equalized according to the area and field. In addition, it would be good to include private higher education institutions. Comparing the situation in public and private higher education institutions can incentivize faster and more intensive digitalization. The results of such research can offer new insights into approaches to digital transformation, both from the point of view of the integration of digital technologies into everyday business and from the point of view of planning and implementing it. 


\section{References}

1. Alcatel-Lucent Enteprise (2019), "Why Digital Transformation for Education? - FAQ Digital Transformation", available at: https://www.al-enterprise.com//media/assets/internet/documents/digital-transformation-faq-en.pdf (4 April 2019)

2. Clark, E. (2018), "Digital Transformation: What is It?", available at: https://er.educause.edu/articles/2018/5/digital-transformation-what-is-it (5 April 2019)

3. Đurek, V., Divjak, B., Begičević Ređep, N. (2018), "Dokument o metodologiji procjene digitalne zrelosti - case study", available at: http://higherdecision.foi.hr/sites/default/files/D14.7.5\%20Metodologija\%20procjene\%2 Oe-spremnosti\%20\%E2\%80\%93\%20case\%20study\%20za\%20RH.pdf (13 June 2018)

4. EHL Insights (2020), "Top 8 digital transformation trends in education", available at: https://hospitalityinsights.ehl.edu/digital-transformation-trends-education (13 June 2020)

5. Kokkinakos, P., Markaki, O., Koussouris, S., Psarras, J. (2016), "Digital transformation: is public sector following the enterprise 2.0 paradigm?", in Digital Transformation and Global Society, Springer International Publishing, Cham, pp. 96-105.

6. Matković, P., Tumbas, P., Marić, M., Raković, L. (2018), "Digital Transformation of Research Process at Higher Education Institutions", Proceedings of INTED2018 Conference (5-7 March 2018), Valencia, Spain.

7. Nunnally, J. C., Bernstein, I. H. (1994), "The Assessment of Reliability", Psychometric Theory, Vol. 3, pp. 248-292.

8. Sandkuhl, K., Lehmann, H. (2017), "Digital Transformation in Higher Education - The Role of Enterprise Architectures and Portals", in: Rossmann, A., Zimmermann, A. (Eds.), Digital Enterprise Computing, Gesellschaft für Informatik, Bonn, pp. 49-60.

9. Setia, P., Venkatesh, V., Joglekar, S. (2013), "Leveraging Digital Technologies: How Information Quality Leads to Localized Capabilities and Customer Service Performance", MIS Quarterly, Vol. 37 No. 2, pp. 565-590.

10. Spear, E. (2019), "7 examples of digital transformation in higher education", available at: https://www.ecampusnews.com/2019/07/15/7-examples-of-digital-transformationin-higher-education/ (5 June 2020)

\section{About the authors}

Mirela Mabic works at the Faculty of Economics, University of Mostar, at the Department for Business Informatics. Her research interests include digital transformation, business information systems, the practical application of software and web technologies in business and education, higher education quality, and applied statistics. The author can be contacted at mirela.mabic@ef.sum.ba

Daniela Garbin Praničević, Ph.D., is an Associate Professor of business informatics at the Faculty of Economics, Business, and Tourism, University of Split. Her M.A. degree is received in Information Management at the Faculty of Economics, University of Zagreb, and the Ph.D. degree in Business Informatics at the Faculty of Economics, Business, and Tourism, University of Split. Her research interests are knowledge management, ICT project management, and ICT appliance in education and business, particularly in tourism and hospitality. She participated in a few research projects and published papers based on the project results. The author can be contacted at daniela@efst.hr 